\title{
Seismic Performance of Non-overflow Gravity Dam Considering Dam-rock Coupling Effect
}

\author{
Cong Zeng ${ }^{1}$, Dongxue Hao ${ }^{1}$, Liqun $\mathrm{Hou}^{1}$, Wen $\mathrm{Pan}^{2}$, Hexian $\mathrm{Su}^{2}$ \\ ${ }^{1}$ Department of Architectural Engineering, Northeast Dianli University, Jilin, 132012, China \\ ${ }^{2}$ Department of Architectural Engineering, Kunming University of Science and Technology, Kunming, 650500, China
}

\begin{abstract}
Theoretical profile stress and displacement of a certain non-overflow gravity dam in a key water-control project was studied in this paper. Plane finite element method and dam-rock coupling effect were both considered. It is concluded that the tensile stress concentration was appeared at the heel and toe of dam, especially the dam heel with significant compression. Therefore, the former position is of great importance in the design. However, the stress is still less than the strength of dam concrete and foundation rock, which is means the seismic design of the non-overflow gravity is reasonable. Moreover, it is indicated that the damrock coupling effect will significantly affect the simulation results.
\end{abstract}

Keywords-dam-rock coupling effect; plane finite element method; non-overflow gravity dam; seismic performance

\section{INTRODUCTION}

The non-overflow gravity dam means the dam without overflow. In most of the key gravity dam engineering, the overflow dam are always in the middle riverbed or main stream, and the non-overflow dams are in the both side, connecting to the bank and isolated by abutment pier and guide wall. The engineering background of this paper is the non-overflow gravity dam in Yunnan province, Nujiang drainage basin. The foundation is weakweathered calcite dolomite and dolomite limestone. The width and height of dam is $5.0 \mathrm{~m}$ and $34.5 \mathrm{~m}$ separately with the top elevation EL.824.50m. The grade of upstream side is $90^{\circ}$, and the downstream side is 1:0.75. For the small cross section, C20 concrete (W8, F100, 3grading ) is adopted. The site of dam is located in the region of 7 degree seismic fortification intensity, where is the interface between 7 and 8 degree. The peak value of earthquake acceleration is $0.15 \mathrm{~g}$, predominant period is $0.3 \mathrm{~s}$. To guarantee the seismic safety, the non-overflow dam was numerical simulated by ANSYS based on plane finite element method. The deformation and stress distribution in different earthquake cases were studied, meanwhile, the weak parts were revealed according to the simulation results.

\section{CALCULATION ASSUMPTION AND CASE SETTING}

It is specified in the Chinese code ${ }^{[1]}$ that: during the seismic calculation of non-overflow dam, only normal pool level is considered on the upstream water level, and the earthquake also only combine with the normal pool level situation. Only the earthquake along the river is considered. The seismic loads to be considered are earthquake inertia force, hydrodynamic pressure under lateral earthquake. Other acting forces such as the uplift pressure, silt pressure, dynamic earth pressure and hydrodynamic pressure under vertical earthquake are ignored. The representative value of hydrodynamic pressure under lateral earthquake can be converted to the corresponding added mass in the dam surface.

Two loading combination patterns were considered as follows: (1) basic combination of normal pool level; (2) accidental combination of earthquake and check flood. The basic combination is including dead weight of dam's concrete, static water pressure in both upstream and downstream and uplift pressure. In the accidental combination, earthquake action is composed of lateral earthquake and $2 / 3$ vertical earthquake, along with the overall consideration of static and dynamic response.

\section{PLAN FINITE ELEMENT SIMULATION ON THE NON- OVERFLOW DAM}

\section{A. Parameters and FEM model}

FEM software ANSYS was adopted in this paper to simulate the non-overflow dam and its foundation. Firstly, the theoretical profile according to the self-weight, hydrostatic pressure and seepage pressure is modelled by ANSYS, which can satisfy the requirements of strength, stability, construction and economy. To accurately consider the dam-rock coupling effect and reflect the elastic dynamic effect of foundation, the foundation rock was modelled, and its dimension on upstream, downstream and depth are all set the value of twice height of the dam. Plane42 element in ANSYS was selected both in the dam concrete and foundation rock. The reversed added mass of hydrodynamic pressure was modelled by MASS21 element in ANSYS ${ }^{[2]}$. The material parameters are shown in the Table 1.

TABLE I. MATERIAL PARAMETERS IN THE ANSYS SiMULATION

\begin{tabular}{ccccc}
\hline Material & $\begin{array}{c}\text { Elasticity modulus } \\
(\mathrm{Mpa})\end{array}$ & $\begin{array}{c}\text { Poisson's } \\
\text { ratio }\end{array}$ & $\begin{array}{c}\text { Density } \\
\left(\mathrm{Kg} / \mathrm{m}^{3}\right)\end{array}$ & $\begin{array}{c}\text { Dynamic } \\
\text { compressive/tensile } \\
\text { strength (Mpa) }\end{array}$ \\
\hline concrete & $2.55 \mathrm{E}+10$ & 0.2 & 2450 & $8.93 / 1.67$ \\
rock & $2.5 \mathrm{E}+09$ & 0.28 & 2600 & $1.31 /-$ \\
\hline
\end{tabular}

For the non-overflow dam is constructed by concrete, the following terms are regulated by current specification 
in China ${ }^{[1]}$ : in earthquake case, the dynamic modulus of elasticity and bearing capacity of concrete can be 30\% increase compare to static case; the dynamic modulus of deformation and bearing capacity of rock can also be $30 \%$ increase compare to static parameters; Shearing strength for both earthquake and static cases are the same.

4-node plane strain element was chosen to simulate the dam and rock. A 2D FEM model was established, which is consist of a concrete gravity dam and a foundation 2 times higher than the dam. The boundary condition of the bottom and surroundings is defined as linkage constraints. The total quantity of FEM model is 6786 with 7012 joints. Concern to the coordinate system, along the river to the downstream is $\mathrm{X}$ axis positive, straight up is $\mathrm{Y}$ axis positive. In the ANSYS stress results, positive value is tensile stress, and negative value is pressure stress. The 2D ANSYS model is shown in Fig 1.

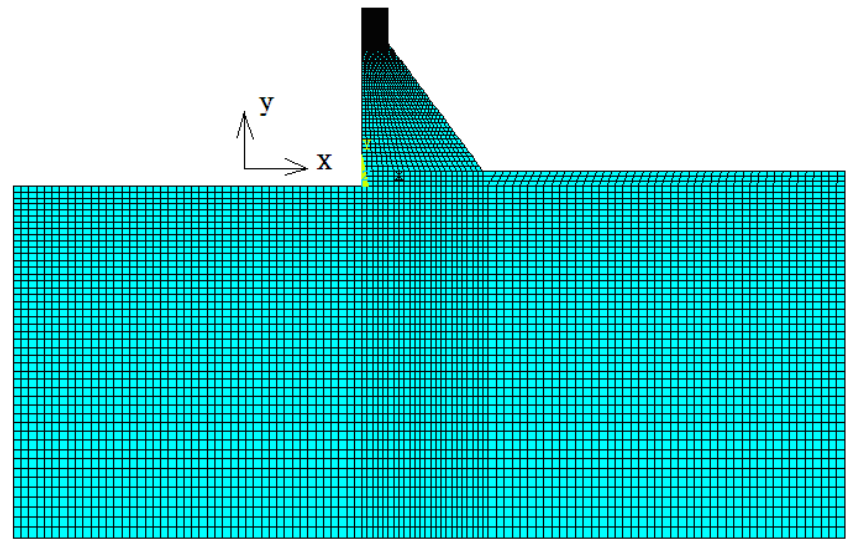

Figure 1. Plane finite element model of the non-overflow dam

\section{B. Mode analysis results}

According to the mode analysis results, low order frequency dominated the earthquake response of the nonoverflow gravity dam. The effective mass ratio of first 3 orders reached up to $98.9 \%$, whereas, the first 6 orders of modes were extracted in the spectral analysis. The results indicated that the mode shape conformed to the general rules, as shown in Fig.2. No adverse mode shape appeared. The natural frequency of reservoir full is less than the reservoir empty. The first 8 orders of nature frequencies were combined by SRSS method, which were listed in table 2 .

TABLE II. FIRST 6 ORDERS NATURAL FREQUENCY OF THE NONOVERFLOW DAM UNIT: Hz

\begin{tabular}{lcccccc}
\hline Mode & 1 & 2 & 3 & 4 & 5 & 6 \\
\hline Full & 4.1010 & 7.8714 & 11.069 & 24.011 & 43.928 & 45.759 \\
Empty & 4.6966 & 8.0209 & 12.579 & 25.862 & 48.825 & 54.582 \\
\hline
\end{tabular}
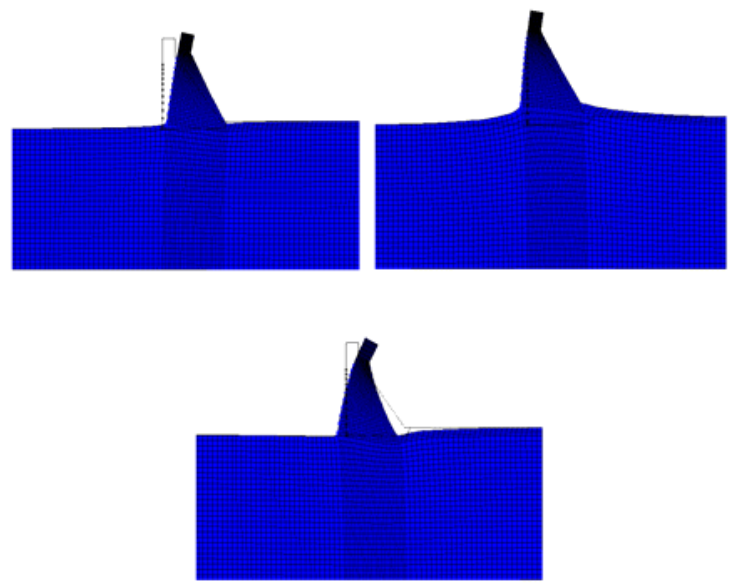

(a) First order

(b) Second order

(c) Third order

Figure 2. First 3 orders of vibration modes

\section{Stress results by ANSYS}

Firstly, the stress distribution of normal pool level case (case (1)) and check flood case (case (2)) were studied. Then the static case of normal pool level was combined with the other two dynamic cases, such as frequently occurrence earthquake case (case (3)) and rarely occurrence earthquake (case (4)). The obtained contour lines of theoretical profile on stress distribution under above mentioned cases were demonstrated in Fig.3.

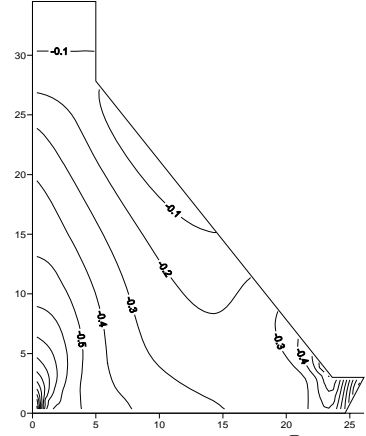

(a) Case (1)

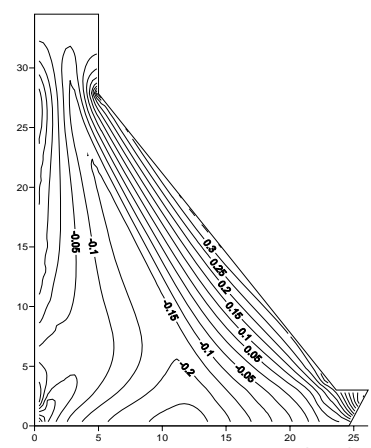

(c) Case (1)+3

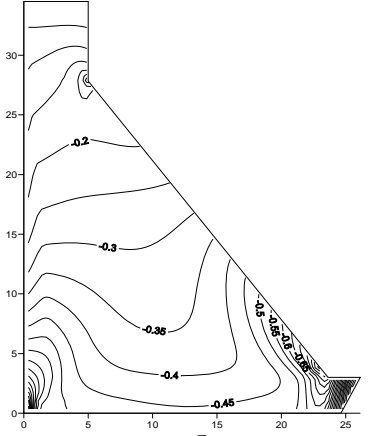

(b) Case (2

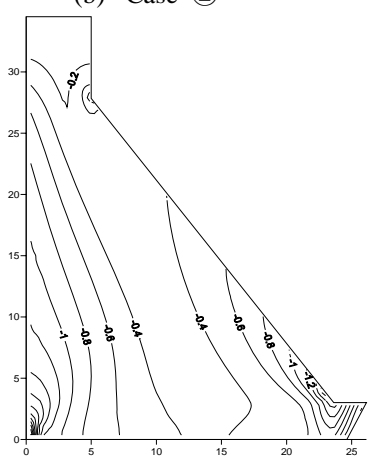

(d) Case (1)-(3) 


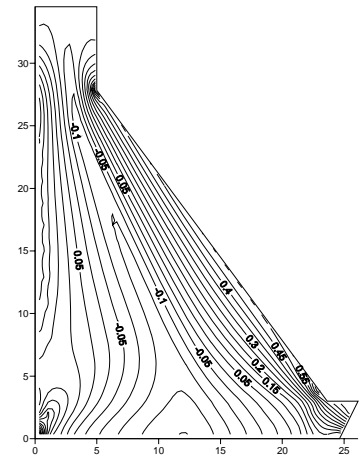

(e) Case (1)+(4)

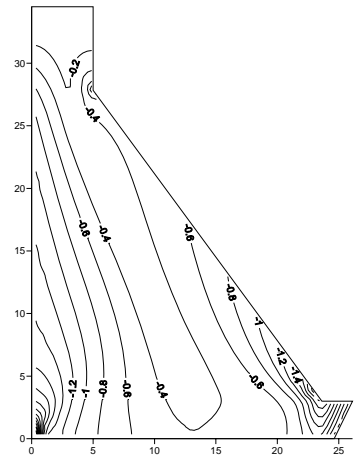

(f) Case (1)-(4)
Figure 3.Von Mises of theoretical profile of the non-overflow gravity dam

By analyzing the Fig.3, the maximum stress and its position were listed in Table 3. It can be concluded that stress concentration appeared in the heel of upstream and toe of downstream, where need to be carefully pay attention to. Moreover, no maximum stress listed is exceeding the strength of concrete and rock listed in Table 1.

TABLE III. MaXimum And Position Of Von Mises StRESS

UNIT: MPA

\begin{tabular}{|c|c|c|c|c|}
\hline \multirow{2}{*}{ Case } & \multicolumn{2}{|c|}{ Stress in the upstream } & \multicolumn{2}{|c|}{ Stress in the downstream } \\
\hline & maximum & position & maximum & position \\
\hline (1) & -0.489 & dam heel & -0.398 & dam toe \\
\hline (2) & -0.631 & dam heel & -0.528 & dam toe \\
\hline (1) + (3) & 0.334 & dam heel & 0.470 & dam toe \\
\hline (1)-(3) & -1.099 & dam heel & -0.955 & dam toe \\
\hline (1) + (4) & 0.493 & dam heel & 0.626 & dam toe \\
\hline (1)-(4) & -1.301 & dam heel & -1.148 & dam toe \\
\hline
\end{tabular}

\section{Displacement results by ANSYS}

Displacement of the non-overflow dam was listed in Table 4. The maximal displacement along the river appeared at the upstream dam heel, and the maximal vertical displacement is at upstream dam top. This conclusion seems strange. It will be explained in next section.

TABLE IV. SUMMERY OF MAXIMAL DISPLACEMENT UNIT: MM

\begin{tabular}{|c|c|c|c|c|}
\hline \multirow{2}{*}{ CASE } & \multicolumn{2}{|c|}{ Along the river } & \multicolumn{2}{|c|}{ Vertical } \\
\hline & maximum & position & maximum & position \\
\hline (1) & 1.32 & Heel upstream & -3.04 & $\begin{array}{c}\text { Top } \\
\text { upstream }\end{array}$ \\
\hline (2) & 2.14 & Top downstream & -2.35 & $\begin{array}{c}\text { Toe } \\
\text { upstream }\end{array}$ \\
\hline (1) \pm (3) & 9.37 & Top downstream & -6.06 & $\begin{array}{c}\text { Top } \\
\text { upstream }\end{array}$ \\
\hline (1) \pm (4) & 12.19 & Heel upstream & -7.07 & $\begin{array}{c}\text { Toe } \\
\text { upstream }\end{array}$ \\
\hline
\end{tabular}

\section{INFLUENCE ON ANSYS RESULTS BY DAM-ROCK COUPLING EFFECT}

It is indicated that the value of rock elasticity modulus may affect the displacement significantly. Take the results of case (1) as example. When the rock elasticity modulus valued as infinity, which means that the boundary condition was treated as completely rigid constraint without considering the dam-rock coupling effects, the maximal displacement along the river appeared at the top of dam with the value of $0.49 \mathrm{~mm}$ and the vertical displacement of dam top was $0.14 \mathrm{~mm}$, and no displacement at the dam heel, shown as Fig.4(a). However, when the dam-rock coupling effects was considered, and the rock elasticity modulus valued as $2.9 \mathrm{Gpa}$, the maximal displacement along the river appeared at dam heel with the value of $1.32 \mathrm{~mm}$, and the maximal displacement along the river at the dam top was $0.52 \mathrm{~mm}$. The vertical displacement at the dam heel was $-2.93 \mathrm{~mm}$, and the value at dam top was $-0.34 \mathrm{~mm}$, as shown in Fig.4(b). According to the above results, it is concluded that the rock elasticity modulus significantly affect the dam top displacement in the direction of along the river and vertical, but no noticeable influence on the displacement of dam heel along river direction. Therefore, all the obtained displacements in ANSYS were global. Because the heel displacement along the river is more than the dam top, makes it seem to incline to the back of dam.

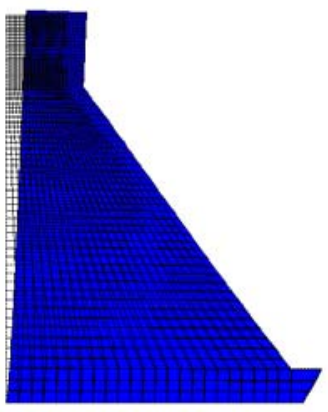

(a)

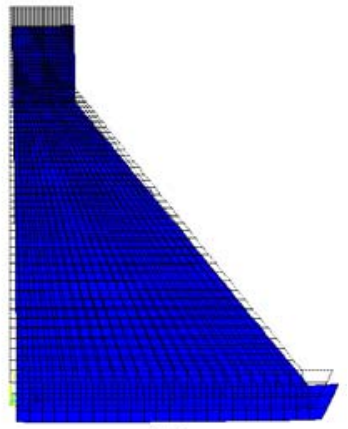

(b)
Figure 4. Dam displacement under different rock elasticity modulus

\section{V.CONCLUSIONS}

According to the numerical simulation results, adverse stress state may appear in the non-overflow dam during earthquake. Noticeable stress concentration may occur in dam heel, dam toe and toe corners, especially tensile stress. After the combination of static and dynamic response, the displacement was not enough to cause the dam leakage. By considering all kinds of cases and damrock coupled effect, the maximal Von Mises stress was still in safe range.

\section{ACKNOWLEDGEMENTS}

The research work was supported by National Natural Science Foundation of China under Grant No. 51308094, No. 51308095. 


\section{REFERENCES}

[1] Specification for Seismic Design of Hydraulic Structure (DL57032001). The State Economic and Trade Commission of China, 2001. (in Chinese)
[2] Su Hexian, Pan Wen, Yang Jianrong, Lai Zhengcong. Study on Seismic Performance of the Non-overflow Gravity Dam. Science Technology and Engineering,10(26), pp.77-83,2010. (in Chinese) 